angle of the edge, not on the shape and size of the flake itself. There is a most interesting discussion on the relationship between the role of hand-axes and flake tools in the stone tool assemblages, which of course is pertinent to our understanding of the changing use of stone as a raw material between the Lower and Middle Palaeolithic industries, hand-axes being much rarer in the latter. It is unfortunate that so far very little microwear information has been collected on handaxes. As Keeley points out, "there is much potential for future research".

The implication of Keeley's conclusions in this section is that microwear data can provide unique information on the use of stone by allowing us to relate empirically the form of artifacts to their utilized parts. Furthermore, such data can provide the sole source of information on an aspect of the evolution of human behaviour which has received little discussion by archaeologists - the consumption of resources: their uses, maintenance and discard. But it seems that Keeley does not recognize this broader significance of his work.

Similarly, the two concluding chapters are somewhat disappointing. They discuss, respectively, areas for future research and the conclusions of the study so far, and both are characterized by a surprising modesty and lack of ambition. The conclusions of the microwear analysis of the prehistoric assemblages which Keeley (p.176) feels are the most important are that it has ". . . uncovered many fascinating details about the technology of the Lower Palaeolithic, not the least of which are the existence of plant 'gathering' knives and information about the methods of hide preparation employed"; furthermore, it has "uncovered some interesting relationships between the morphology and function of implements in the assemblages . . .", and it has provided a "little tantalizing information pertinent to questions concerning the purposes of hand-axes in the Middle Acheulian . . .". But is microwear analysis - all those hours and energy - destined to provide only the "fascinating", the "tantalizing" and the "interesting"'? Likewise, the suggestions for future research tend to concentrate on particular details and problems.

In this book there is an enormous amount of valuable experimental and analytical information, which should have an impact on a wide public. Keeley warns about many of the traps of microwear analysis, including over-confidence and over-optimism. He fails, though, to mention the most dangerous one of all: that one can fall in love with one's flake edges, especially when they are viewed under the microscope, and forget why it is that we originally decided to spend so much time with them.

Ruth Tringham is Associate Professor of Anthropology at the University of California at Berkeley.

\title{
Natural history from Henry VII to Victoria
}

\section{G. D. R. Bridson}

British Natural History Books, 14951900: A Handlist. By R.B. Freeman. Pp.437. ISBN 0-7129-0971-0/0-208-01790-0. (Dawson, Folkestone, Kent/Archon, Hamden, Connecticut: 1980.) $£ 20, \$ 39.50$.

MODEST proportions and unpretentious presentation combine to disguise this book's place as a milestone in the progress of British natural history bibliography. We have never had an equivalent of, for instance, Meisel's magnificent bibliography of American natural history down to 1865 , though such works as Simpson and Henrey for botany, and Irwin and Lisney for ornithology and entomology, have made significant contributions. Otherwise one could turn to the German compilations of Engelmann, Carus and Taschenberg for a bibliography of general natural history and zoology down to 1880 , amongst which is buried British material.

The compilation of a checklist of all British natural history books is a task for the experienced bibliographer and we are fortunate that one so well qualified as $\mathrm{Dr}$ Freeman should attempt the task. The result is a work that does great credit to him and outstanding service to the user. It is only a handlist but within that format lies much concealed scholarship and great attention to accuracy. This is enhanced by providing the full forenames of every author possible, by searching out and recording multiple editions, by providing a chronology of pre-1801 titles and by indicating in the index "those works which, in the opinion of the author, are the most important contributions to the subject of the entry". The 35-page subject index extends the value of the book beyond that of a handlist, though that still remains its basic function and as such it is remarkably comprehensive. One can find omissions among its 4,206 entries by crosschecking with works such as Jackson's guide to botanical literature or Taschenberg's general natural history listings. But, I must stress, so much is included that only specialists in book rarities will find fault.

What is more controversial is the exclusion of papers in periodicals and, unfortunately, any bibliographical

In celebration of the centenary of the British Museum (Natural History), the Museum and Cambridge University Press have published Chance, Change and Challenge, a two-volume illustrated compilation which will be of particular interest to sixth-formers and undergraduates. Volume 1, The Evolving Earth, deals with the origin and development of the Earth, and Vol. 2, The Evolving Biosphere, examines the evolution of life. Prices are: Vol. 1 hbk $£ 30$, pbk $£ 10.50$; Vol.2 hbk $£ 32.50$, pbk £11.50. reference to the periodicals themselves. This a handlist of books, but just when a preprint, offprint, reprint or plain tear-out becomes a separate book will give rise to much argument in many individual cases. So many papers from periodicals were reprinted, often with new pagination, in the nineteenth century that the full record of this transition literature will take many years to document with accuracy. The exclusion of bibliographical mention of periodicals is, in my view, the book's most serious omission and one that would not have required so much effort to rectify.

Librarians, bibliographers, historians, book-collectors, booksellers and naturalists will all want this work on their shelves for frequent reference, and several of those will wish to interleave and annotate their copies. They will find few. typographical errors to correct, an odd binary entry to delete perhaps (for example Nos. 439 and 1,181 ), and a few crossreferences to add here and there. At $£ 20$ the book is rather costly for such commonplace presentation but in terms of intrinsic value and likely duration of utility that cost will be amply rewarded.

G. D. R. Bridson is Librarian at the Linnean Society of London.

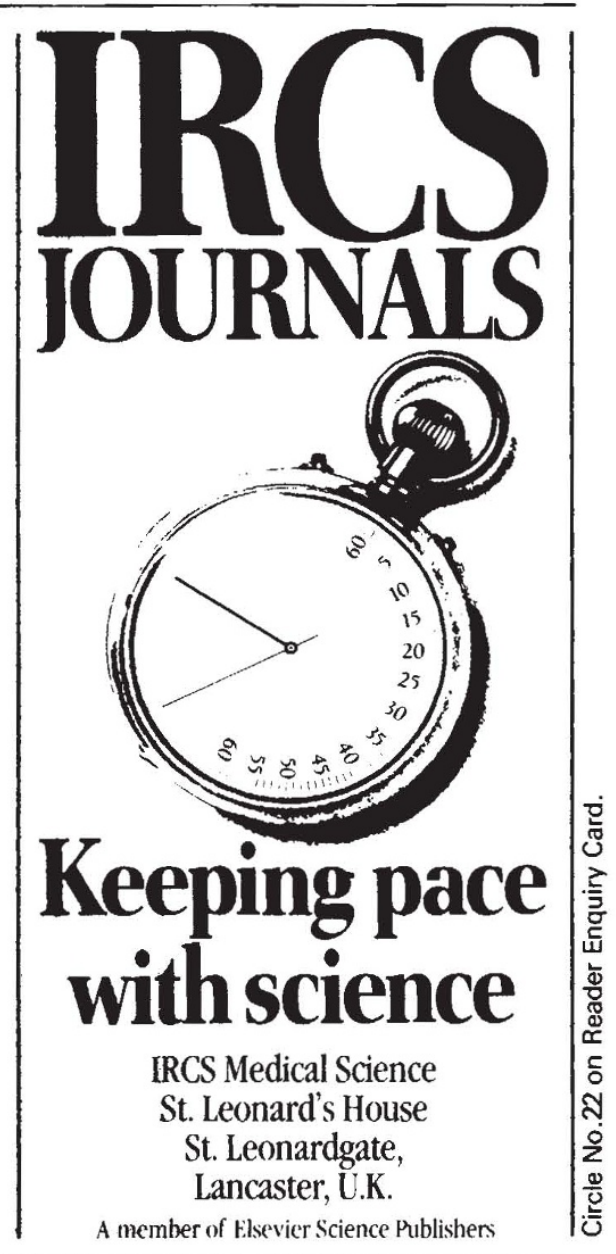

